\title{
MALONDIALDEHYDE IN TYPE 2 DIABETICS AND ASSOCIATION WITH CARDIOVASCULAR RISK FACTORS
}

\author{
Shalash, M. ${ }^{(1)}$, Badra, M. ${ }^{(1)}$, Imbaby, S. ${ }^{(2)}$, EIBanna E. ${ }^{(3)}$ \\ 1) Department of Internal Medicine, Faculty of Medicine, Alexandria University, Egypt. \\ 2) Department of Chemical and Clinical pathology, Faculty of Medicine, Alexandria University, Egypt. \\ 3) Department of $\mathrm{MBBCH}$, Alexandria University.
}

\section{ABSTRACT}

Background: Type 2 diabetes mellitus (T2DM) is a progressive chronic disease with high prevalence all over the world. It is expected to have 693 million people affected by diabetes by 2045 . Many body systems are affected due to complications of DM with major effect on the cardiovascular system. Dyslipidemia is one of the major risk factors for cardiovascular disease in diabetes mellitus. Malondialdehyde (MDA) is a highly toxic end product formed by lipid oxidation that mediates its toxic effects due to its high reactivity particularly towards proteins and DNA. Malondialdehyde interacts both irreversibly and reversibly with proteins and phospholipids causing profound effects, especially in the collagen of the cardiovascular system. Normally, MDA level remains within normal values due to antioxidant effects, but in DM these protective effects are disrupted.

Objective: Measure serum Malondialdehyde level as a marker of lipid peroxidation in type 2 diabetic patients and its association with other cardiovascular risk factors.

Patients and methods: The study included 40 diabetic patients recruited from Outpatient Diabetes Clinic at Alexandria Main University Hospital in addition to healthy 40 healthy subjects as a control group. Basic data, clinical examination and laboratory analysis were obtained from all the subjects within the two groups. Serum Malondialdehyde (MDA) was measured in the participants within the two groups by using ELISA kit.

Results: The mean serum MDA level was statistically significant higher in the diabetic cases as compared to the controls (Median MDA was $30.72 \mathrm{nmol} / \mathrm{ml}$ in cases and $25.16 \mathrm{nmol} / \mathrm{ml}$ in the control). There is a significant increase in serum MDA level with increasing the risk of CV disease in the whole study subjects and in the diabetic cases. In the cases group MDA shows positive correlation with all the study parameters except high density lipoproteins (HDL) where it revealed negative correlation. BY ROC curve analysis, a cutoff point more than $>26.57$ had $62.5 \%$ sensitivity, $70 \%$ specificity, $66.4 \%$ positive predictive value (PPV) and $72.5 \%$ negative predictive value (NPV).

Conclusion: Malondialdehyde is a non-invasive biomarker that could be utilized in differentiation of T2DM cases form healthy controls in addition for identifying the high-risk diabetic patients for cardiovascular disease (CVD). However, further large-scale studies are recommended to accurately determine its sensitivity and specificity.

Keywords: Malondialdehyde, lipid peroxidation, oxidative stress, cardiovascular diseases.

\section{INTRODUCTION}

Diabetes Mellitus (DM) is a chronic disease that represents a major health problem affecting all age groups all over the world. It is a group of metabolic diseases due to carbohydrate metabolism disorder characterized by elevated blood glucose as a result of defect in secretion, action of insulin hormone or both. The classical presenting triad of DM includes polyuria, polydipsia and polyphagia as direct consequences of increased blood glucose levels. Many long-term complications occur with chronic state of hyperglycemia. Different organs are affected especially the eyes, kidneys, nerves, heart, and blood vessels. ${ }^{(1)}$

In 2019, it is estimated that 463 million people aged (20-79) years have diabetes and this number is projected to reach 578 million by 2030, and 700 million by 2045 for the same age group.Two-thirds of people with diabetes live in urban areas and three out of four are of working age. Over four million people aged 20-79 years are estimated to die from diabetes-related causes in $2019^{(2)}$

Type 2 diabetes mellitus (T2DM) is primarily due to lifestyle factors and genetics ${ }^{(3)}$ Many causes are listed for diabetes including: genetic defects of $\beta$-cell function, genetic defects in insulin processing or insulin action, 
exocrine pancreatic defects (Chronic pancreatitis, Pancreatectomy) Pancreatic neoplasia, Cystic fibrosis, hemochromatosis, fibrocalculous pancreatopathy, endocrinopathies (acromegaly, Cushing syndrome, hyperthyroidism, pheochromocytoma, glucagonoma), infections and drugs. ${ }^{(4)}$

Atherosclerotic cardiovascular disease remains the main cause of death and disability among patients with diabetes. ${ }^{(5)}$ Dyslipidemia is a major risk factor for adverse cardiovascular events. ${ }^{(6)}$ High levels of low density lipoproteins (LDL) and low levels of HDL are associated with myocardial infarction and stroke. ${ }^{(7)}$

Malondialdehyde (MDA) is a highly toxic side way product that occur during the lipid oxidation by free radicals. The concentrations of MDA are increased in patients with T2DM. ${ }^{(8)}$

Malondialdehyde interacts both irreversibly and reversibly with proteins and phospholipids leading to harmful effects. In particular; the collagen of the cardiovascular system is not only stiffened by cross-links mediated by Malondialdehyde, but also this collagen later becomes increasingly resistant to remodeling. ${ }^{(9)}$ The toxicity of Malondialdehyde arises from its high reactivity particularly towards proteins and DNA. ${ }^{(10)}$

In normal conditions, lipid oxidation is controlled by antioxidant activity of different body systems. It has been suggested that Localized deficiency of antioxidants would allow more lipid oxidation to occur. ${ }^{(11)}$

Malondialdehyde is used as a putative marker of lipid oxidation both in plasma and in arterial lesions. There is now substantial evidence that both oxidized low density lipoprotein (ox-LDL) and Malondialdehyde occur in the atherosclerotic plaque. ${ }^{(12)}$

However, there is a debate about the relation between MDA levels and duration of type $2 \mathrm{DM}$ in the course of persistent rise in metabolic parameters. ${ }^{(13,14)}$

\section{PATIENTS AND METHODS}

This is a cross sectional case-control study that was conducted in Outpatient Diabetes Clinic at Alexandria Main University Hospital.

The study included 40 patients with T2DM and 40 healthy subjects as a control group. The patients with the following conditions were excluded; smokers, patients taking antioxidant supplements, alcoholic, anemic patients, history of endocrinal diseases, history of hepatic disease and history of severe renal impairment.

All cases were subjected to complete history taking and through clinical examination (with measurement of different body measures). The following laboratory investigations were done for all the cases including: CBC, fasting blood glucose (FBG), glycated hemoglobin (HbA1C), two hour post prandial blood glucose ( $2 \mathrm{~h}$ PPBG), total serum cholesterol., serum HDL, serum LDL, serum triglycerides (TG) and serum uric acid.

Serum malondialdehyde level was measured using human enzyme-linked immunosorbent assay kits (Human malondialdehyde kit; Catalog No. CSBA082431 America).

\section{STATISTICAL ANALYSIS}

Data entered and analyzed using Microsoft Excel software. Data were then imported into Statistical Package for the Social Sciences (SPSS 22.0, IBM/SPSS Inc., Chicago, IL) software for analysis. Baseline characteristics of the study population were presented as frequencies and percentages (\%) or mean values and standard deviations (SD) or median and interquartile range (IQR).

For comparison of data, Chi-Square test (or Fisher's exact test) was used to compare two independent groups of qualitative data. For quantitative data, independentSamples t-test and Mann-Whitney U test were used to compare two groups of parametric and non-parametric quantitative data respectively.

Kruskal Wallis test was used to compare three or more groups of non-parametric quantitative data.

Correlation of numeric data was done by Spearman correlation (r). Receiver operating characteristic (ROC) analysis followed by determination of the optimal cutoff value using Youden index $\mathbf{J}$ were used to analyzed the diagnostic ability of nesfatin-1. $\mathrm{P}$ values $<0.05$ are considered significant.

\section{RESULTS}

The study included 40 type 2 diabetic patients and 40 healthy subjects as a control group. As shown in table (1), there was no statistically significant difference in the age between the two study groups. There were 20 males and 20 females in each group. The different body measures didn't reveal a statistically significant difference between the two groups except for the mean waist circumference that was significantly wider in the cases group as compared to the controls $(106.70 \pm 8.67 \mathrm{~cm}$ and $95.13 \pm$ $8.34 \mathrm{~cm}$ respectively).

Table (2) shows that SBP, TGs levels, serum uric acid level, FBG, 2hPP and HbAlc were significantly higher in the cases group as compared to the controls. The mean level of HDL was statistically significantly lower in the cases group as compared to the controls. Other parameters didn't reveal a statistically significant difference between the two groups. 
Table (1): Comparison between the two studied groups according to demographic data and anthropometric measures

\begin{tabular}{lccc}
\hline & $\begin{array}{c}\text { Cases } \\
(\mathbf{n = 4 0 )}\end{array}$ & $\begin{array}{c}\text { Control } \\
(\mathbf{n}=\mathbf{4 0})\end{array}$ & $\mathbf{P}$ \\
\hline $\begin{array}{l}\text { Gender } \\
\text { Male }\end{array}$ & $20(50 \%)$ & $20(50 \%)$ & $1.000 *$ \\
$\quad$ Female & $20(50 \%)$ & $20(50 \%)$ & $0.131 * *$ \\
\hline Age (years) & $48.63 \pm 9.27$ & $45.73 \pm 7.63$ & $0.288 * *$ \\
\hline Weight (kg) & $89.83 \pm 11.39$ & $87.08 \pm 11.60$ & $0.065 * *$ \\
\hline Height (cm) & $166.2 \pm 6.98$ & $169.0 \pm 6.27$ & $<\mathbf{0 . 0 0 1} * *$ \\
\hline Waist circumference & $106.70 \pm 8.67$ & $95.13 \pm 8.34$ & $0.055^{* *}$ \\
\hline BMI (kg/m2)
\end{tabular}

*: Chi-square test

**: Independent samples t-test

Table (2): Comparison between the two studied groups according to SBP and laboratory parameters

\begin{tabular}{|c|c|c|c|}
\hline Variables & $\begin{array}{c}\text { Cases } \\
(n=40)\end{array}$ & $\begin{array}{l}\text { Control } \\
(n=40)\end{array}$ & $\mathbf{p}$ \\
\hline SBP (mmHg) & $122.8 \pm 13.01$ & $108.3 \pm 9.58$ & $<0.001^{* *}$ \\
\hline T-cholesterol & $162.50 \pm 48.95$ & $146.23 \pm 27.26$ & $0.071^{* *}$ \\
\hline HDL & $44.0(38.50-51.0)$ & $52.0(40.5-68.0)$ & $\mathbf{0 . 0 3 3}{ }^{* * *}$ \\
\hline LDL & $101.0(78.9-129.5)$ & $89.55(50.9-124.2)$ & $0.119^{* * * *}$ \\
\hline TGs & $111.5(96.0-166.5)$ & $97.5(84.0-105.0)$ & $0.004^{* * *}$ \\
\hline S. Uric acid & $5.25(4.3-6.02)$ & $4.5(3.6-5.4)$ & $0.027^{* * * *}$ \\
\hline HB (\%) & $13.55 \pm 0.86$ & $13.52 \pm 1.10$ & $0.901^{* *}$ \\
\hline FBG & $152(115.5-180.0)$ & $81.50(75.0-85.0)$ & $<0.001^{* * * *}$ \\
\hline $2 \mathrm{hPPG}$ & $211.5(147.0-311.5)$ & $100(93.5-109.5)$ & $<0.001^{* * * *}$ \\
\hline $\mathbf{H b A}_{1} \mathbf{c}$ & $8.19 \pm 1.55$ & $5.29 \pm 0.18$ & $<0.001^{* * *}$ \\
\hline
\end{tabular}

**: Independent samples t-test

***: Mann-Whitney U-test

Table (3) shows that 3 cases of the diabetic group had history of pervious revascularization and 12 cases receive hypertension treatment in contrast to the control group where no case showed neither history of pervious revascularization nor previous hypertension treatment. There was high statistically significant difference between the two groups according to the cardiovascular risk $(\mathrm{p}<0.001)$.

The median level of MDA in the cases group was statistically significantly higher as compared to the control group $(\mathrm{p}=0.009)$ as shown in table. ${ }^{(4)}$. 
As shown in table (5), in the whole study population, there is a statistically significant positive correlation between MDA levels and waist circumference, BMI, SBP, T. Cholesterol, LDL, FBG, 2-hour post prandial glucose, cardiovascular risk, HbA1c and TG levels. There was a statistically significant negative correlation between
MDA levels and HDL levels. In the cases group, there is a statistically significant positive correlation between MDA levels and waist circumference, BMI, SBP, T. Cholesterol, LDL, FBG, HbA1c, cardiovascular risk and TG levels. There was a statistically significant negative correlation between MDA levels and HDL level.

Table (3): Comparison between the two studied groups according to history of pervious revascularization, HTN treatment and CV risk

\begin{tabular}{|c|c|c|c|c|c|}
\hline & \multicolumn{2}{|c|}{$\begin{array}{c}\text { Cases } \\
(\mathrm{n}=40) \\
\end{array}$} & \multicolumn{2}{|c|}{$\begin{array}{l}\text { Control } \\
(n=40)\end{array}$} & \multirow[t]{2}{*}{$\mathbf{P}$} \\
\hline & No. & $\%$ & No. & $\%$ & \\
\hline History of pervious revascularization & 3 & 7.5 & - & - & - \\
\hline HTN treatment & 12 & 30.0 & 0 & 0.0 & $<0.001^{*}$ \\
\hline \multicolumn{6}{|l|}{ CV risk } \\
\hline Low risk & 0 & 0.0 & 18 & 45.0 & \\
\hline Moderate & 5 & 12.5 & 21 & 52.5 & \multirow{3}{*}{$<0.001^{*}$} \\
\hline High & 32 & 80.0 & 1 & 2.5 & \\
\hline Very high & 3 & 7.5 & 0 & 0.0 & \\
\hline
\end{tabular}

*: Chi-square test

Table (4): Comparison between the two studied groups according to MDA

\begin{tabular}{ccccc} 
& MDA & $\begin{array}{c}\text { Cases } \\
(\mathbf{n}=40)\end{array}$ & $\begin{array}{c}\text { Control } \\
(\mathbf{n}=40)\end{array}$ & $\mathbf{p}$ \\
\hline Median (IQR) & $\mathbf{3 0 . 7 2 ( 2 2 . 6 7 - 5 5 . 7 4 )}$ & $\mathbf{2 5 . 1 6}(\mathbf{2 2 . 0 9}-27.29)$ & $\mathbf{0 . 0 0 9} * * *$ \\
\hline
\end{tabular}

***: Mann-Whitney U-test

Table (5): Correlation between MDA and different parameters in all study subjects and in cases group.

\begin{tabular}{|c|c|c|c|c|}
\hline & \multicolumn{2}{|c|}{ All study subjects $(n=80)$} & \multicolumn{2}{|c|}{ Cases group $(n=40)$} \\
\hline & \multicolumn{2}{|c|}{ MDA } & \multicolumn{2}{|c|}{ MDA } \\
\hline & $\mathbf{r}_{\mathrm{s}}$ & $\mathbf{p}$ & $\mathbf{r}_{\mathrm{s}}$ & $\mathbf{p}$ \\
\hline Waist circumference & $0.377^{*}$ & $0.001^{*}$ & $0.382^{*}$ & $0.015^{*}$ \\
\hline BMI $\left(\mathrm{kg} / \mathrm{m}^{2}\right)$ & $0.272^{*}$ & $0.017^{*}$ & $0.360^{*}$ & $0.022^{*}$ \\
\hline SBP & $0.403^{*}$ & $<0.001^{*}$ & $0.472^{*}$ & $0.002^{*}$ \\
\hline T. Cholesterol & $0.377^{*}$ & $0.001^{*}$ & $0.382^{*}$ & $0.015^{*}$ \\
\hline LDL & $0.309^{*}$ & $0.005^{*}$ & $0.338^{*}$ & $0.033^{*}$ \\
\hline HDL & $-0.298^{*}$ & $0.007^{*}$ & $-0.450^{*}$ & $0.004^{*}$ \\
\hline S-uric acid & 0.111 & 0.326 & 0.119 & 0.465 \\
\hline FBG & $0.455^{*}$ & $<0.001^{*}$ & $0.654^{*}$ & $<0.001^{*}$ \\
\hline 2hPPG & $0.226^{*}$ & $0.044^{*}$ & 0.152 & 0.350 \\
\hline CV risk & $0.323^{*}$ & $0.003^{*}$ & $0.408^{*}$ & $0.009^{*}$ \\
\hline HbA1c & $0.378^{*}$ & $0.001^{*}$ & $0.448^{*}$ & $0.004^{*}$ \\
\hline TG & $0.571^{*}$ & $<0.001^{*}$ & $0.785^{*}$ & $<0.001^{*}$ \\
\hline
\end{tabular}

$\mathbf{r}_{\mathrm{s}}:$ Spearman coefficient $\quad *$ : Statistically significant at $\mathrm{p} \leq 0.05$


As shown in table (6), there was a statistically significant increase in the level of MDA in the serum according to the cardiovascular risk where the cases with very high risk of cardiovascular disease have the highest level of MDA.
As shown in table (7), the best cutoff point of MDA to differentiate between cases with type 2 DM and control group was > 26.57 with $62.5 \%$ sensitivity, $70 \%$ specificity, 66.4\% PPV and $72.5 \%$ NPV

Table (6): Relation between CV risk and MDA in cases group $(n=40)$

\begin{tabular}{|c|c|c|c|c|}
\hline \multirow[b]{2}{*}{ MDA } & \multicolumn{3}{|c|}{ CV risk } & \multirow[b]{2}{*}{$\mathbf{p}$} \\
\hline & $\begin{array}{l}\text { Moderate } \\
\quad(\mathbf{n}=\mathbf{5})\end{array}$ & $\begin{array}{c}\text { High } \\
(n=32)\end{array}$ & $\begin{array}{l}\text { Very high } \\
\quad(\mathbf{n}=\mathbf{3})\end{array}$ & \\
\hline Min. - Max. & $14.3-73.96$ & $13.6-80.0$ & $110.0-115.0$ & \multirow{2}{*}{$0.011^{*}$} \\
\hline Median & 26.04 & 30.72 & 112.0 & \\
\hline Sig. bet. grps & \multicolumn{3}{|c|}{$\mathrm{p}_{1}=0.365, \mathrm{p}_{2}=0.004^{*}, \mathrm{p}_{3}=0.006^{*}$} & \\
\hline
\end{tabular}

$\mathrm{p}: \mathrm{p}$ value for comparing between the studied groups

$\mathrm{p}_{1}$ : $\mathrm{p}$ value for comparing between moderate and high

$\mathrm{p}_{2}: \mathrm{p}$ value for comparing between moderate and very high

$\mathrm{p}_{3}: \mathrm{p}$ value for comparing between high and very high

*: Statistically significant at $\mathrm{p} \leq 0.05$

Table (7): Predictive ability of serum MDA to differentiate between cases and control

\begin{tabular}{lc}
\hline & \multicolumn{2}{c}{ Serum MDA } \\
Cut off point & 0.670 \\
Sensitivity & $>26.57$ \\
Specificity & $62.5 \%$ \\
PPV & $70 \%$ \\
NPV & $66.4 \%$ \\
P & \multicolumn{2}{c}{$\mathbf{7 2 . 5 \%}$} \\
\cline { 2 - 2 }
\end{tabular}

AUC: Area under curve, PPV: positive predictive value, NPV: Negative predictive value

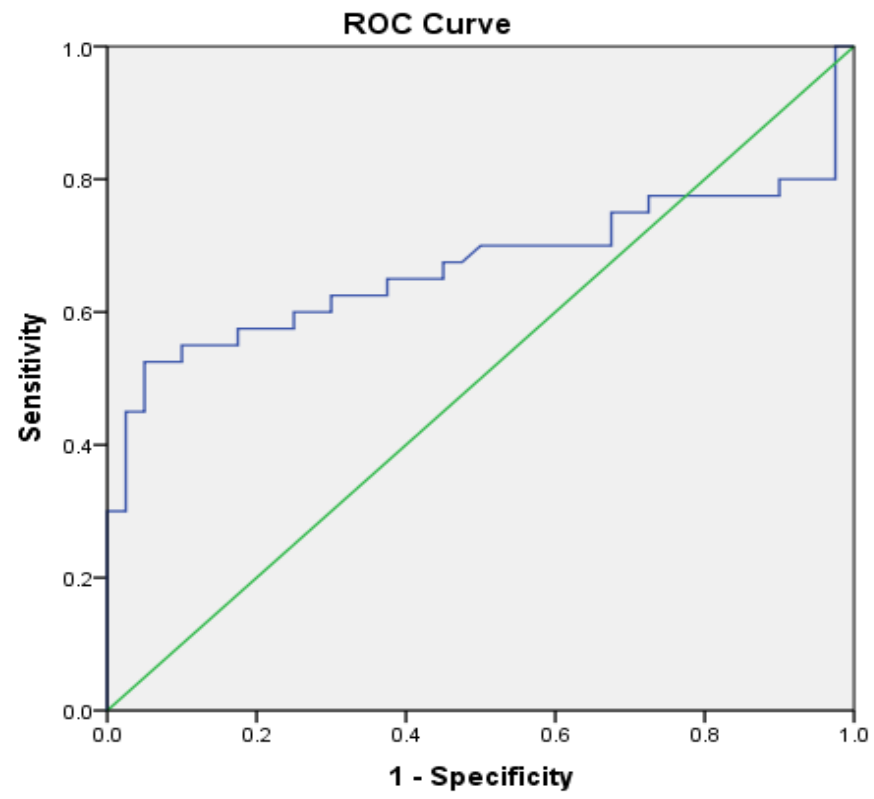

Figure (1): ROC curve for Predictive ability of serum MDA to differentiate between cases and contro

\section{DISCUSSION:}

This current study was conducted to measure serum MDA levels in type 2 diabetes patients as a reliable marker of lipid peroxidation and investigate its relationship to cardiovascular risk factors. Our study was conducted on 80 subjects of whom 40 patients were type 2 diabetics and 40 were healthy subjects as a control group.

The two groups were matched in terms of age, sex, and socioeconomic class. The mean age of the diabetic group was $48.63 \pm 9.27$, and $45.73 \pm 7.63$ for the control. There was no significant difference in age between the two groups ( $\mathrm{p}$ value $<0.13$ ).

CVD risk factors include old age, smoking, systemic hypertension, diabetes, dyslipidemia, decreased physical exercise and poor diet. ${ }^{(15)}$

Dyslipidemia manifested as high LDL, high TG and low HDL is an important risk factor for development of CVD. Current guidelines focus on lowering LDL cholesterol 
with statins in both primary and secondary preventive situations. ${ }^{(16-18)}$ This approach is supported by evidence from large perspective studies. In a recent analysis of 14 statin studies including 90,056 patients, decreasing LDL by $39 \mathrm{mg} / \mathrm{dl}$ was associated with about one fifth reduction in the 5-year incidence of major CV events. ${ }^{(19)}$

Recently, oxidative stress has become a focus of interest in most medical disciplines and an area of wide research work. Increasing evidence shows that oxidative stress is associated with the pathogenesis of diabetes and recent studies suggest a possible relationship between lipid peroxidation and diabetes complications. ${ }^{(9)}$

Oxygen free radicals and lipid peroxides have been implicated in the pathogenesis of a large number of diseases such as DM, cancer, rheumatoid arthritis and atherosclerosis. MDA is a highly toxic by product formed in part by lipid oxidation from free $\mathrm{O}_{2}$ radicals, and many studies reported its higher levels in DM, reacting both reversibly and irreversibly with proteins and phospholipids with serious consequences. ${ }^{(9)}$

Cardiovascular diseases remain the main cause of morbidity and mortality among patients with DM. DM contributes to atherosclerosis and heart failure through many mechanisms. ${ }^{(20)}$ Framingham Heart Study (1974) showed a direct association between diabetes and heart failure. ${ }^{(21)}$

There is recent evidence that increased oxidative stress in DM contributes to the development of diabetic complications. ${ }^{(22)}$ Oxygen derived free radicals interact with the lipid bilayer in cell membranes leading to its peroxidation. ${ }^{(23)}$ MDA is a stable end product of lipid peroxidation and its measurement is considered a reliable marker of oxidative damage. ${ }^{(24)}$

Our results demonstrated significantly higher levels of MDA in diabetic patients than the control group at a $\mathrm{P}$ value of 0.009 with a mean serum MDA level of $41.57 \pm 28.04$ in diabetics while the mean level in the control group was $24.95 \pm 5$.

Many studies have reported higher levels of MDA in diabetics than healthy subjects as found by Bhutia et al. (2011). ${ }^{(25)}$ Soliman GZA ${ }^{(26)}$ and Rani et al. (2005). ${ }^{(27)}$

Rani et al also observed lower total antioxidant status values in the type 2 diabetic group compared to the control group and concluded that there is an increased oxidative stress in diabetics compared to their nondiabetic counterparts and emphasized the importance of assessing these markers for early diagnosis and therapeutic interventions. ${ }^{(27)}$

Our findings were also in accordance with Mahreen et al. (2010) (a study performed on a sample of Indian subjects). ${ }^{(28)}$ The study Participants were divided to 3 groups, 30 diabetic T2DM without any complications, 30 T2DM patients with myocardial infarction (MI) and 30 healthy subjects as control group. The results demonstrated a significantly higher levels of MDA in the diabetic group compared to the control. In addition to that, a significantly higher MDA level was observed in the T2DM group with myocardial infarction compared to the T2DM without complications.

They gave two probable explanations for these findings either the longer disease duration or increased glycation of serum proteins which leads to increased activation of receptors for advanced glycation end products which initiates the process of atherosclerosis . ${ }^{(28)}$

An Increased level of MDA in diabetics suggests that peroxidative injury may be involved in the development of diabetic complications. The increase in lipid peroxidation is also an indication of decline in defense mechanisms of enzymatic and non-enzymatic antioxidants. ${ }^{(29)}$

Increased MDA level in plasma, serum, and many other tissues has been reported in diabetic patients. ${ }^{(30,31)}$ In 1991, Baynes, followed by Ramesh et al in 2012. ${ }^{(23,32)}$ reported that lipid peroxidation in diabetes induced many secondary chronic complications including ather-osclerosis and neural disorders. Yang et al., (2009) observed greater serum lipid peroxidation evaluated in terms of MDA in hyperglycemic mice and proposed that the increase in lipid peroxidation exacerbated the occurrence of myocardial infarction through NADPH oxidase activation ${ }^{(33)}$

Our results demonstrated a significant correlation between fasting blood glucose ( FBG) levels and higher MDA levels in type 2 diabetes cases $(\mathrm{P}<0.001)$ which agreed with Manohar et al. (2013) who found a statistically significant positive correlation between MDA levels and FBG in newly diagnosed type 2 diabetic patients and, hence concluded an association between hyperglycemia and oxidative stress. ${ }^{(34)}$

Our results also demonstrated a statistically significant positive correlation between $\mathrm{HbA} 1 \mathrm{C}$ and MDA level in the diabetic group which coincides with findings by Whiting et al., (2008) who concluded that chronic hyperglycemia can affect the production of free radicals which can eventually lead to increased lipid peroxidation and consumption of antioxidants and hence, increased oxidative stress in diabetic subjects. ${ }^{(35)}$

A clinical study performed by Bandeira and coworkers (2012) aimed at characterizing blood oxidative stress in diabetic patients reported significantly higher lipid peroxidation which showed a close relationship with high glucose levels as observed by the fasting glucose and HbA1c levels. ${ }^{(31)}$

Contrary to these findings are results by Hanachi et al.,(2009) who found no significant correlation between MDA level and fasting blood sugar (FBS) or glycated hemoglobin in both cases and the control group, but they found significantly higher levels of MDA in diabetics compared to the control group [36] which is in accordance with our results. 
We found a significantly higher TG level in diabetic than the control group ( $p$ value $=0.004$ ) which contradicts results from Hanachi et al., (2009) who found no significant difference, ${ }^{(36)}$ but agrees with Tangvarasittichai et al., (2009) who observed significantly higher TG levels in diabetics than the control group. ${ }^{(37)}$

Our results also showed significantly lower levels of HDL in diabetics than control $(\mathrm{p}$ value $=0.033$ ) which agree with findings by Soliman ${ }^{(26)}$ Hanachi et al. (2009) ${ }^{(36)}$ and Tangvarasittichai et al. (2009) ${ }^{(37)}$

When comparing TC level, it did not differ significantly between the two groups ( $p$ value $=0.071$ ) which was in line with findings by Hanachi et al. (2009) ${ }^{(36)}$ who also found no significant difference between both groups, it was contrary to the findings of Tangvarasittichai et al. (2009), ${ }^{(37)}$ Soliman ${ }^{(26)}$ and Rani et al., (2005), ${ }^{(27)}$

In regards to LDL levels there was no significant difference between the two groups ( $p$ value $=0.119$ ), which contradicts findings by Soliman GZA ${ }^{(26)}$ (2008), Hanachi et al. (2009) (36) and Tangvarasittichai et al. (2009). ${ }^{(37)}$

When correlating serum MDA levels to lipid profile parameters in the diabetic group, we found significant positive correlation to TC, TG, and $\mathrm{LDL}$ at $\mathrm{p}$ values of $(0.015,<0.001,0.033)$ respectively which was similar to findings by Tangvarasittichai et al., (2009) ${ }^{(37)}$ and Hamad et al. (2009) ${ }^{(38)}$ However, Hamad et al., (2009) disagree with our finding of significant inverse correlation between serum MDA level and HDL a ( $p$ value of 0.0040), as they found no significant relation between HDL level and MDA in type 2 diabetic patients. However, many other studies found significant negative correlation between MDA level and HDL in type 2 diabetic patients. Of these studies, one performed by Sharma et al., (2017), ${ }^{(39)}$ which was conducted with the aim of evaluating levels of Apo A-V proteins and markers of inflammation and oxidative stress in patients of T2DM with and without hypertriglyceridemia and also to assess correlation between them. By analyzing their data, they demonstrated significant negative correlation between MDA level and HDL in all subjects (type 2 diabetics with and without hypertriglyceridemia) at $\mathrm{P}$ value of 0.001 .

Moreover, some studies have revealed significant negative correlation between MDA and HDL in type 2 diabetics with complications like that performed by Aldebasi et al. (2013) (40) in Al Quassim University in Kingdom of Saudi Arabia. The study included 54 patients with type 2 DM (21 with proliferative diabetic retinopathy and 33 without proliferative diabetic retinopathy) and 30 healthy subjects. Their results demonstrated that patients with proliferative diabetic retinopathy were characterized by significantly low HDL-C ( $\mathrm{P}=0.017)$ and high MDA (P $<0.001$ ) when compared to their diabetic counterparts without retinopathy. In patients with proliferative diabetic retinopathy, Pearson correlation analysis revealed the plasma concentration of MDA had a significant negative correlation to HDL-C $(\mathrm{p}=0.030)$ and ApoA1 $(\mathrm{p}=0.045)$.
The authors concluded that since both HDL-C and Apolipoprotein A1 have been reported to have antioxidant effects, ${ }^{(41)}$ the inverse correlation between MDA and HDL - C may point to the role of oxidative stress in the pathogenesis of diabetic retinopathy.

Our results demonstrate significantly higher mean serum uric acid in diabetics than the control group $(\mathrm{P}=0.027)$ which agreed with findings by Satoru et al. ${ }^{(42)}$ Hazem Ahmed et al. ${ }^{(43)}$ This finding of higher uric acid levels in diabetics can be explained by hyperinsulinemia as a consequence of insulin resistance that causes an increase in serum uric acid by reducing its renal excretion and accumulation in its substrates. ${ }^{(44)}$ Many other studies reported positive associations between high serum uric acid and diabetes 蜉 (45-47) while others reported no association ${ }^{(48)}$ and others found negative association. ${ }^{(49)}$

We also noticed a significant positive correlation between waist circumference (central obesity) in diabetics and serum MDA levels which is similar to findings by Fernando Moreto et al. (2014). They studied determinants of higher plasma MDA in a group of healthy adults at high risk or with metabolic syndrome, and found that subjects with higher plasma MDA differed from others by showing higher values of waist circumference, fasting blood glucose, TG, and energy intake, ${ }^{(50)}$ Tangvarasittichai et al reported the same observation in 2009 . $^{(37)}$

Our results also demonstrated significant positive correlation between serum MDA and systolic blood pressure in type $2 \mathrm{DM}$ at $\mathrm{p}$ value $=0.002$ which can be explained by the deleterious effects of MDA on vascular system.

This finding coincides with findings from a study performed by Dominguez et al. (2010). ${ }^{(51)}$ The Study evaluated oxidative stress parameters and hyperhomocysteinemia (as known independent risk factors for cardiovascular disease that occur more frequently in old age) in relation to age and the presence of hypertension and type 2 DM. Their results demonstrated that MDA levels were significantly higher in older versus younger subjects without hypertension or DM at $\mathrm{P}$ value $<0.001$. Interestingly, MDA did not differ significantly in older versus younger hypertensive subjects and in older versus younger diabetic hypertensive subjects. From the previous data, authors concluded that aging is accompanied by elevated oxidative stress level similar to those observed in younger subjects with hypertension or DM independently from age. Hence, these conditions seem to accelerate the age dependent increase in oxidative stress.

A similar finding was observed by Tangvarasittichai et al at Naresuan University in Thiland. ${ }^{(37)}$ this study reported a significantly higher MDA level in type 2 diabetics than the control group and significant positive correlation with systolic blood pressure (SBP) and diastolic blood pressure (DBP).

In the same context, a study performed by Ekeanyanwu $\mathrm{RC}$ et al in Faculty of Science in Nijeria aiming at 
measuring the antioxidant vitamins $\mathrm{C}, \mathrm{E}$ levels and lipid peroxidation status in hypertensive patients and diabetic hypertensive patients receiving vitamin supplements, insulin and lipid lowering drugs revealed that there was a weak positive correlation between Thiobarbituric acid reactive substances $-\mathrm{MDA}$ and $\mathrm{SBP}$ in diabetic hypertensive patients $(\mathrm{P}=0.339){ }^{(52)}$

In order to test the independent effect of different study parameters on MDA level in cases group, a multivariate linear regression analysis was done which revealed a significant positive correlation between FBG and MDA at $\mathrm{p}$ value $=0.019$. This finding is consistent with an observation reported by Manohar et al. in (2013). (34) They found initially a significant positive correlation between MDA level and FBG in newly diagnosed type 2 diabetic (using Pearson Correlation). This significant positive correlation was retained even after nullifying the effect of lipid parameters. Therefore, we suggest that lipid parameters cannot be the only main cause of oxidative stress in DM. Importantly, these correlation analyses also suggest that hyperglycemia per se is greatly involved in oxidative stress resulting in increased lipid peroxidation, and consequently higher plasma MDA levels.

The Multivariate Linear regression analysis also demonstrated a significant positive correlation between TG level and MDA in cases group at $\mathrm{p}$ value $<0.001$ which is similar to findings by Bakhtiari et al., in 2017 who studied the independent effect of different metabolic syndrome components (according to ATP 111 criteria) on MDA level in a group of elderly Iranian females with metabolic syndrome. They found that TG was the factor most strongly associated with MDA, followed by HDL-C ${ }^{(53)}$

\section{CONCLUSION}

Malondialdehyde is a non-invasive biomarker that could be utilized in differentiation of T2D cases form healthy controls in addition to identifying the high-risk diabetic patients for $\mathrm{CV}$ disease.

\section{Conflict of Interest}

Authors declare no conflicts of interest.

\section{REFERENCES}

1. Fitzmaurice C, Allen C, et al. Global, regional, and national cancer incidence, mortality, years of life lost, years lived with disability, and disability-adjusted lifeyears for

2. Zimmet P. Diabetes epidemiology as a tool to trigger diabetes research and care. Diabetologia. 1999;42 (5): 499.

3. Edition I. International Diabetes Federation. IDF Diabetes Atlas, 8th edn. Brussels, Belgium: International Diabetes Federation, 2017.

4. Risérus U, Willett WC, Hu FB. Dietary fats and prevention of type 2 diabetes. Progress in lipid research. 2009;48(1):44-51.
5. Sattar N, Preiss D, Murray HM, Welsh P, Buckley BM, de Craen AJ, et al. Statins and risk of incident diabetes: a collaborative meta-analysis of randomised statin trials. The Lancet. 2010;375(9716):735-42.

6. Beckman JA, Paneni F, Cosentino F, Creager MA. Diabetes and vascular disease: pathophysiology, clinical consequences, and medical therapy: part II. European heart journal. 2013; 34(31):2444-52.

7. Wong ND. Epidemiological studies of CHD and the evolution of preventive cardiology. Nature Reviews Cardiology. 2014; 11(5):276.

8. Holmes MV, Millwood IY, Kartsonaki C, Hill MR, Bennett DA, Boxall R, et al. Lipids, lipoproteins, and metabolites and risk of myocardial infarction and stroke. Journal of the American College of Cardiology. 2018; 71(6):620-32.

9. Jalali M, Pouya S, Eshraghian A, Rajab A, Chamari M, Fatehi F, et al. Effects of $\omega 3$ on serum level of malondialdehyde and homocysteine in type 2 diabetic patients. Armaghane danesh. 2008; 12(4):45-53.

10. Slatter D, Bolton C, Bailey A. The importance of lipidderived malondialdehyde in diabetes mellitus. Diabetologia. 2000; 43(5):550-7.

11. Giera M, Lingeman H, Niessen WM. Recent advancements in the LC-and GC-based analysis of malondialdehyde (MDA): a brief overview. Chromatographia. 2012;75(910):433-40.

12. Domínguez R, Pateiro M, Gagaoua M, Barba FJ, Zhang W, Lorenzo JM. A comprehensive review on lipid oxidation in meat and meat products. Antioxidants. 2019;8(10):429.

13. Senders ML, Que X, Cho YS, Yeang C, Groenen H, Fay $\mathrm{F}$, et al. PET/MR imaging of malondialdehydeacetaldehyde epitopes with a human antibody detects clinically relevant atherothrombosis. Journal of the American College of Cardiology. 2018;71(3):321-35.

14. Brownlee M, Cerami A, Vlassara H. Advanced glycosylation end products in tissue and the biochemical basis of diabetic complications. New England Journal of Medicine. 1988; 318(20):1315-21.

15. Nakhjavani M, Esteghamati A, Nowroozi S, Asgarani F, Rashidi A, Khalilzadeh O. Type 2 diabetes mellitus duration: an independent predictor of serum malondialdehyde levels. Singapore medical journal. 2010; 51 (7):582

16. Tzoulaki I, Elliott P, Kontis V, Ezzati M. Worldwide exposures to cardiovascular risk factors and associated health effects: current knowledge and data gaps. Circulation. 2016;133(23):2314-33.

17. Detection NCEPEPo, Adults ToHBCi. Third report of the National Cholesterol Education Program (NCEP) Expert Panel on detection, evaluation, and treatment of high blood cholesterol in adults (Adult Treatment Panel III): National Cholesterol Education Program, National Heart, Lung, and Blood ...; 2002.

18. Grundy SM, Cleeman JI, Daniels SR, Donato KA, Eckel RH, Franklin BA, et al. Diagnosis and management of the metabolic syndrome: an American Heart Association/ National Heart, Lung, and Blood Institute scientific statement. Circulation. 2005;112(17):2735-52

19. Brunzell JD, Davidson M, Furberg CD, Goldberg RB, Howard BV, Stein JH, et al. Lipoprotein management in patients with cardiometabolic risk: consensus statement from the American Diabetes Association and the American College of Cardiology Foundation. Diabetes care. 2008;31(4):811-22. 
20. Unit ES. Efficacy and safety of cholesterol-lowering treatment: prospective meta-analysis of data from 90 056 participants in 14 randomised trials of statins. Lancet (London, England). 2005;366(9493):1267-78.

21. Low Wang CC, Hess CN, Hiatt WR, Goldfine AB. Clinical update: cardiovascular disease in diabetes mellitus: atherosclerotic cardiovascular disease and heart failure in type 2 diabetes mellitus-mechanisms, management, and clinical considerations. Circulation. 2016;133(24):2459-502

22. Singer DE, Nathan DM, Anderson KM, Wilson PW, Evans JC. Association of HbA1c with prevalent cardiovascular disease in the original cohort of the Framingham Heart Study. Diabetes. 1992;41(2):202-8.

23. Baynes JW, Thorpe SR. Role of oxidative stress in diabetic complications: a new perspective on an old paradigm. Diabetes. 1999;48(1):1-9.

24. Baynes JW. Role of oxidative stress in development of complications in diabetes. Diabetes. 1991;40(4):405-12

25. Mayes PA, Botham KM. Lipids of physiologic significance. Harper's biochemistry. 2000;24:146-57.

26. Bhutia Y, Ghosh A, Sherpa ML, Pal R, Mohanta PK. Serum malondialdehyde level: Surrogate stress marker in the Sikkimese diabetics. Journal of natural science, biology, and medicine. 2011;2(1):107.

27. Soliman G. Blood lipid peroxidation (superoxide dismutase, malondialdehyde, glutathione) levels in Egyptian type 2 diabetic patients. Singapore medical journal. 2008;49(2):129.

28. Rani HS, Madhavi G, Rao VR, Sahay B, Jyothy A. Risk factors for coronary heart disease in type II diabetes mellitus. Indian journal of clinical biochemistry. 2005;20(2):75-80

29. Mahreen R, Mohsin M, Nasreen Z, Siraj M, Ishaq M. Significantly increased levels of serum malonaldehyde in type 2 diabetics with myocardial infarction. International journal of diabetes in developing countries. 2010;30(1):49.

30. Saddala RR, Thopireddy L, Ganapathi N, Kesireddy SR. Regulation of cardiac oxidative stress and lipid peroxidation in streptozotocin-induced diabetic rats treated with aqueous extract of Pimpinella tirupatiensis tuberous root. Experimental and Toxicologic Pathology. 2013;65(1-2):15-9.

31. Moussa S. Oxidative stress in diabetes mellitus. Romanian J biophys. 2008;18(3):225-36.

32. Bandeira SdM, Guedes GdS, Fonseca LJSd, Pires AS, Gelain DP, Moreira JCF, et al. Characterization of blood oxidative stress in type 2 diabetes mellitus patients: increase in lipid peroxidation and SOD activity. Oxidative medicine and cellular longevity. 2012;2012.

33. Ramesh B, Karuna R, Sreenivasa RS, Haritha K, Sai $\mathrm{MD}$, Sasis BRB, et al. Effect of Commiphora mukul gum resin on hepatic marker enzymes, lipid peroxidation and antioxidants status in pancreas and heart of streptozotocin induced diabetic rats. Asian Pacific journal of tropical biomedicine. 2012;2(11):895900.

34. Yang Z, Laubach VE, French BA, Kron IL. Acute hyperglycemia enhances oxidative stress and exacerbates myocardial infarction by activating nicotinamide adenine dinucleotide phosphate oxidase during reperfusion. The Journal of thoracic and cardiovascular surgery. 2009;137(3):723-9.

35. Manohar SM, Vaikasuvu SR, Deepthi K, Sachan A, Narasimha SRPVL. An association of hyperglycemia with plasma malondialdehyde and atherogenic lipid risk factors in newly diagnosed Type 2 diabetic patients. Journal of Research in Medical Sciences: The Official Journal of Isfahan University of Medical Sciences. 2013;18(2):89.

36. Whiting P, Kalansooriya A, Holbrook I, Haddad F, Jennings $P$. The relationship between chronic glycaemic control and oxidative stress in type 2 diabetes mellitus. British journal of biomedical science. 2008;65(2):71-4.

37. Moghadam RH, Latiffah A. Investigation of lipid profiles and lipid peroxidation in patients with type 2 diabetes. European Journal of Scientific Research. 2009;28(1):6-13

38. Tangvarasittichai S, Poonsub $\mathrm{P}$, Tangvarasittichai $\mathrm{O}$, Sirigulsatien V. Serum levels of malondialdehyde in type 2 diabetes mellitus Thai subjects. Siriraj Medical Journal. 2009;61(1).

39. Hamad MS, Khalaf SJ, Sarhat ER. Relationship between malondialdehyde activity (MDA) \&Lipid Profile in Diabetic Patients. Tikret Journal of Pharmaceutical Sciences. 2009;5(1):27-32.

40. Sharma D, Garg S, Mehndiratta M, Madhu S, Puri D. Relationship of serum apolipoprotein AV levels, oxidative stress and inflammatory biomarkers with hypertriglyceridemia in type 2 diabetes mellitus. International journal of endocrinology and metabolism. 2017; 15(2).

41. Aldebasi YH, Mohieldein AH, Almansour YS, Almutairi BL. Dyslipidemia and lipid peroxidation of Saudi type 2 diabetics with proliferative retinopathy. Saudi Med J. 2013;34(6):616-22.

42. Miranda PJ, DeFronzo RA, Califf RM, Guyton JR. Metabolic syndrome: evaluation of pathological and therapeutic outcomes. American heart journal. 2005; 149(1):20-32.

43. Gersch C, Palii SP, Kim KM, Angerhofer A, Johnson RJ, Henderson GN. Inactivation of nitric oxide by uric acid. Nucleosides, Nucleotides and Nucleic Acids. 2008; 27(8):967-78

44. Ahmed HA. Assessment of Plasma Malondialdehyde and Uric Acid among Sudanese Patients with Type-2 Diabetes Mellitus in Khartoum State.

45. Chien K-L, Chen M-F, Hsu H-C, Chang W-T, Su T-C, Lee Y-T, et al. Plasma uric acid and the risk of type 2 diabetes in a Chinese community. Clinical chemistry. 2008; 54(2):310-6.

46. Dehghan A, Van Hoek M, Sijbrands EJ, Hofman A, Witteman JC. High serum uric acid as a novel risk factor for type 2 diabetes. Diabetes care. 2008; 31(2):361-2.

47. Kramer CK, Von Mühlen D, Jassal SK, Barrett-Connor E. Serum uric acid levels improve prediction of incident type 2 diabetes in individuals with impaired fasting glucose: the Rancho Bernardo Study. Diabetes care. 2009; 32(7):1272-3.

48. Nakanishi N, Okamoto M, Yoshida H, Matsuo Y, Suzuki K, Tatara K. Serum uric acid and risk for development of hypertension and impaired fasting glucose or Type II diabetes in Japanese male office workers. European journal of epidemiology. 2003;18(6): 523-30

49. Taniguchi Y, Hayashi T, Tsumura K, Endo G, Fujii S, Okada K. Serum uric acid and the risk for hypertension and Type 2 diabetes in Japanese men: The Osaka Health Survey. Journal of hypertension. 2001;19(7):1209-15.

50. Oda E, Kawai R, Sukumaran V, Watanabe K. Uric acid is positively associated with metabolic syndrome but negatively associated with diabetes in Japanese men. Internal medicine. 2009;48(20):1785-91. 
51. Moreto F, de Oliveira EP, Manda RM, Burini RC. The higher plasma malondialdehyde concentrations are determined by metabolic syndrome-related glucolipotoxicity. Oxidative medicine and cellular longevity. 2014; 2014.

52. Dominguez LJ, Galioto A, Pineo A, Ferlisi A, Ciaccio $\mathrm{M}$, Putignano E, et al. Age, homocysteine, and oxidative stress: relation to hypertension and type 2 diabetes mellitus. Journal of the American College of Nutrition. 2010;29(1):1-6.
53. Ekeanyanwu R, Ejiogu R, Egbogu M. Lipid peroxidation and non-enzymatic antioxidants status in hypertension in diabetic and non-diabetic patients in Nigeria: a comparative study. 2016.

54. Bakhtiari A, Hajian- Tilaki K, Omidvar S, Nasiri Amiri F. Association of lipid peroxidation and antioxidant status with metabolic syndrome in Iranian healthy elderly women. Biomedical Reports. 2017;7 (4):331-6. 